\title{
Autonomic nervous system activity is independently associated with the risk of shift in the non-dipper blood pressure pattern
}

\author{
Virginie Dauphinot ${ }^{1,2}$, Philippe Gosse ${ }^{3}$, Michel P Kossovsky ${ }^{4}$, Anne-Marie Schott ${ }^{5}$, Isabelle Rouch ${ }^{2}$, \\ Vincent Pichot ${ }^{6}$, Jean-Michel Gaspoz ${ }^{4}$, Frédéric Roche ${ }^{6}$ and Jean-Claude Barthelemy ${ }^{6}$
}

An insufficient decrease in nocturnal blood pressure (BP) is a known factor in cardiovascular mortality. We aimed to determine whether autonomic nervous system (ANS) activity and its change over 2 years were associated with a shift to non-dipper status, independently of initial BP, in a general elderly population. From participants in the PROOF study, 600 subjects untreated for hypertension were selected (age at baseline: 65 years, men: 41.5\%). Dipper/non-dipper status was defined using repeated measures of 24-h ambulatory BP at baseline and 2 years later. ANS activity was evaluated on the basis of 24-h heart rate variability at both examinations. Among the 454 dipper subjects at baseline, $26.2 \%$ became non-dippers. Multivariate analysis showed that $a+1$ between-subject s.d. increase in the very low frequency at baseline was associated with a decreased odds ratio for the shift to non-dipper status 2 years later $(O R=0.61$ [0.41-0.91], $P=0.02)$. The within-subject change between the two measurements of day and night systolic BP and day diastolic BP also contributed significantly to the risk of shift to non-dipper status. Our results suggest that impaired ANS activity precedes an insufficient decrease in nocturnal BP independent of hypertension status.

Hypertension Research (2010) 33, 1032-1037; doi:10.1038/hr.2010.130; published online 29 July 2010

Keywords: ambulatory blood pressure; heart rate variability; non-dipper; sympathetic nervous activity

\section{INTRODUCTION}

An insufficient decrease in nocturnal blood pressure (BP) (nondipping) is recognized as a marker of end-organ damage and a predictor of cardiovascular and all-cause mortality, independently of hypertension status. ${ }^{1-3}$ Our understanding of the pathophysiologic factors that may be involved in the mechanisms of the circadian variation of BP and the non-dipping pattern remains incomplete. Among the suspected determinants, autonomic nervous system (ANS) activity is shown to be associated with arterial BP level and involved in the control of the circadian variation of $\mathrm{BP}^{4,5}$ Previous cross-sectional studies have shown that ANS activity, evaluated by heart rate variability (HRV), was reduced in non-dipper, untreated hypertensive subjects. ${ }^{6,7}$ A possible explanation of the nocturnal decrease in BP is that it results from a reduction of sympathetic nervous activity and impaired circadian rhythm in sympatho-vagal balance during sleep. ${ }^{8,9}$

We aimed to assess whether ANS activity indices and their changes over 2 years, as evaluated by 24-h HRV, were associated with a shift to non-dipper status among subjects identified as dippers at study entry in a general elderly population not treated for hypertension.

\section{METHODS}

Study population

This study sample was selected from participants in the PROOF study, a prospective observational cohort of 1011 age-matched subjects at baseline. The PROOF study was designed to assess the prognostic values of ANS activity in cardiovascular morbidity and mortality. The population included subjects selected from an electoral list of 65-year-old people living in the town of Saint-Etienne, France, in 2001. The design of the PROOF study has been previously published. ${ }^{10}$

In this study, we excluded subjects who were being treated for hypertension at inclusion (with angiotensin-converting enzyme inhibitors, angiotensinreceptor blockers, $\beta$-blockers, diuretics, calcium channel blockers or other antihypertensive drugs). This information was collected through subjects' selfreport and confirmed by physicians' prescriptions. We also excluded subjects with inconsistent or missing HRV or BP measurements.

\section{Examination procedure}

Baseline examinations were performed between January 2001 and December 2002 at the University Hospital in Saint-Etienne, France. The second examination was performed between January 2003 and December 2004. An interval of

\footnotetext{
${ }^{1}$ Neurology Unit D, University Medical Hospital, University of Lyon, Lyon, France; ${ }^{2}$ Research Memory Centre Rhône-Alpes, Lyon, France; ${ }^{3}$ Hypertension Unit, Saint André Hospital, University Medical Hospital of Bordeaux, Bordeaux, France; ${ }^{4}$ Department of Community Medicine and Primary Care, University Hospitals of Geneva and University of Geneva, Geneva, Switzerland; ${ }^{5}$ Center of Medical Information, Evaluation, and Research, University Medical Hospital of Lyon, Lyon, France and ${ }^{6} \mathrm{Clinical}$ and Exercise Physiology Laboratory, University Medical Hospital of Saint-Etienne, Saint-Etienne, France Correspondence: DrV Dauphinot, Research Memory Centre Rhône-Alpes, Hôpital des Charpennes, 27 Rue Gabriel Péri, 69100 Villeurbanne, France. E-mail: d_virginie@hotmail.com
}

Received 30 October 2009; revised 19 April 2010; accepted 19 May 2010; published online 29 July 2010 
2 years between the two examinations was ensured for every subject. The protocol of the PROOF study was approved by the institutional research program (National Hospital Program for Clinical Research) and by the local ethics committee (CPPRB Rhône-Alpes Loire, France). All subjects gave informed written consent

\section{HRV measurements}

HRV was measured at each examination using a 24-h electrocardiographic Holter system (Ultima, Duosoft, Novacor, Rueil-Malmaison, France) that allows extraction of the list of RR intervals with a precision of $0.008 \mathrm{~s}$. Each RR interval was manually validated before analysis. HRV was assessed by analyzing RR intervals according to the frequency of the signal represented by successive RR intervals. RR intervals free of arrhythmias were individually selected for HRV analysis.

Frequency domain indices and mean heart rate were calculated as recommended. ${ }^{11}$ All the calculated indices are recognized to provide a reliable estimate of ANS activity. ${ }^{12}$

Among the frequency indices, we analyzed the total frequency power, the high-frequency (HF) peak, the low-frequency (LF) peak, the very-low-frequency (VLF) peak, the ultra-low-frequency peak and the sympathetic balance at night, defined as the ratio LF/HF.

\section{Ambulatory BP monitoring and hypertension status}

Twenty-four-hour ambulatory BP monitoring (ABPM) was assessed at each examination by ambulatory Holter recordings using an auscultatory method (Diasys Integra, Novacor, Rueil-Malmaison, France). The measurements were programmed to be recorded every $15 \mathrm{~min}$ during the day and every $30 \mathrm{~min}$ during the night, with the cuff placed on the non-dominant arm. Average values of systolic and diastolic BP were calculated for the different recording periods: day, night and $24 \mathrm{~h}$. The daytime interval was from 0700 to 2200 hours and the nighttime interval from 2200 to 0700 hours. Hypertensive status was defined as $24-\mathrm{h} A B P M \geqslant 130 / 80 \mathrm{~mm} \mathrm{Hg} \cdot{ }^{13}$

\section{Circadian variations of ABPM and non-dipper status}

The circadian variation of $\mathrm{BP}$ was defined as the ratio of the difference between the day and night systolic measurements to the day systolic measurements. The non-dipper pattern was defined at each examination as a decrease in nocturnal systolic ABPM values of $<10 \%$ relative to diurnal measurement. ${ }^{14}$ The circadian variations of BP after 2 years were studied in quartiles.

Using the two measurements of ABPM, taken with an interval of 2 years, we identified four groups: non-dipper subjects who remained non-dippers 2 years later, non-dipper subjects who became dippers, dippers who remained dippers and dippers who became non-dippers.

\section{Clinical covariates}

Several potential confounding factors, identified at inclusion, were considered: gender, body mass index, self-reported smoking status, fasting glycemia, total cholesterol and score on the abnormal autonomic sleep fragmentation index, an index of sleep-related breathing disorders. ${ }^{15-17}$ In addition, information regarding introduction of an antihypertensive treatment (angiotensin-converting enzyme or angiotensin-receptor blocker, $\beta$-blockers, diuretics, calcium channel blockers or other antihypertensive drugs) between the two examinations was collected at the second examination.

\section{Statistical analysis}

The subjects' characteristics were compared among the four groups according to the dipper/non-dipper status at both examinations to identify potential between-subject differences, using Pearson's $\chi^{2}$ and Fisher's test of ANOVA models as appropriate.

Mean values of the HRV indices and heart rate were compared among the groups using a multivariate ANOVA adjusted for potential confounders. A logarithmic transformation was performed on the HRV indices because their distributions were skewed. The Bonferroni's method was used as a post hoc test to adjust the level of significance for multiple pair-wised comparisons.

Univariate logistic regression models were used to determine whether the ANS activity indices at baseline of the subjects who were dippers at inclusion and their changes between the two examinations were associated with a shift to non-dipper status. The day and night systolic and diastolic BP readings and their change over 2 years were also included in the models.

The variables that were significantly associated with the risk of shift to nondipper status in the univariate models were included in a multivariate step-wise logistic regression.

The within-subject changes of the ANS activity indices between the two examinations were analyzed by categories: a decrease of at least $10 \%$, an increase of at least $10 \%$ and the middle category as reference.

A similar analysis was conducted among the non-dipper subjects at inclusion to identify which indices were associated with a shift in dipping status 2 years later.

We also compared the ANS indices between the quartiles of the circadian variation of BP at 2 years. This was to ensure the consistency of our findings and address the potential lack of reproducibility of non-dipper status. ${ }^{18,19}$

Values were expressed as percentage (number of subjects), mean (s.d.) or odds ratio (confident interval at 95\%). Data were analyzed using the SPSS statistical software package 12.0 for Windows (SPSS Software, Chicago, IL, USA).

\section{RESULTS}

Of the 1011 subjects initially included in the PROOF study, 786 $(77.7 \%)$ were not treated for hypertension. Baseline data were incomplete for 46 subjects; in addition, data were missing for 140 subjects after 2 years of follow-up. The study population consisted of 600 subjects who were present at the two examinations. Among them, 454 were considered dippers.

After 2 years of follow-up, 119 (26.2\%) of the 454 dipper subjects at baseline had shifted to non-dippers, and $71(48.6 \%)$ of the 146 nondipper subjects at baseline had shifted to dippers (Table 1). The subjects' characteristics were statistically significant for day and night BP at baseline and 2 years later, according to dipper/non-dipper status at the two examinations. Day systolic and diastolic BP was higher among the dippers at baseline in comparison with the non-dippers, whereas night values were lower. This held true 2 years later when the same groups were compared.

Without reaching statistical significance, the proportion of men tended to be higher among the non-dippers who became dippers compared with the other groups $(P=0.08)$.

The group of dipper subjects at inclusion who became non-dippers 2 years later had baseline HF, LF and VLF indices significantly lower than the other groups, especially in comparison with the group of dipper subjects who remained dippers (Table 2). The tendency for the other indices was similar even though statistical significance was not reached. There was no significant difference between the group of dipper subjects who remained dippers and the group of non-dipper subjects who remained non-dippers according to the post hoc tests.

Among the dipper subjects at inclusion, the univariate analyses showed that increases in HF, LF and VLF at baseline were associated with lower odds ratios for the shift to non-dipper status 2 years later (Table 3). An increase of at least 10\% of VLF and LF between the two examinations contributed to the shift to non-dipper status 2 years later.

In the multivariate step-wise logistic regression model, the role of baseline VLF remained significant (Table 3). Of note, a within-subject increase of at least 10\% in day BP (systolic or diastolic) was associated with a reduced risk of shift to non-dipper status, whereas the same increase in night systolic BP increased this risk $(\mathrm{OR}=7.62)$. On the contrary, a within-subject decrease of at least $10 \%$ in day systolic BP was associated with a higher risk of shift to non-dipper status $(\mathrm{OR}=3.70)$, whereas the same decrease of night systolic BP carried a lower risk $(\mathrm{OR}=0.15)$. 
Table 1 Descriptive characteristics at baseline and 2 years later of study population according to dipper/non-dipper status

\begin{tabular}{|c|c|c|c|c|c|c|c|c|c|c|c|}
\hline & \multicolumn{2}{|c|}{$D 1 / D 2(\mathrm{n}=335)$} & \multicolumn{2}{|c|}{ D1/ND2 ( $\mathrm{n}=119)$} & \multicolumn{2}{|c|}{$N D 1 / D 2(\mathrm{n}=71)$} & \multicolumn{2}{|c|}{$N D 1 / N D 2(\mathrm{n}=75)$} & \multirow{2}{*}{$\begin{array}{c}\text { (Fisher's test) } \\
\mathrm{P}\end{array}$} & \multicolumn{2}{|c|}{ Total $(\mathrm{n}=600)$} \\
\hline & Mean & s.d. & Mean & s.d. & Mean & s.d. & Mean & s.d. & & Mean & s.d. \\
\hline $\mathrm{BMI}\left(\mathrm{kg} \mathrm{m}^{-2}\right)$ & 24.90 & 3.24 & 24.90 & 3.52 & 24.68 & 3.27 & 24.62 & 3.60 & 0.89 & 24.78 & 3.34 \\
\hline Total cholesterol $\left(\mathrm{mmoll}^{-1}\right)$ & 6.15 & 0.99 & 6.02 & 0.99 & 6.04 & 0.83 & 6.18 & 1.04 & 0.53 & 6.10 & 0.98 \\
\hline Fasting glycemia (mmoll-1) & 5.56 & 0.87 & 5.62 & 1.03 & 5.41 & 1.47 & 5.34 & 1.13 & 0.19 & 5.48 & 1.02 \\
\hline Day systolic ambulatory BP at baseline & 123.44 & 13.66 & 123.20 & 13.58 & 119.14 & 14.12 & 117.24 & 14.26 & 0.001 & 122.12 & 13.93 \\
\hline Day diastolic ambulatory BP at baseline & 79.08 & 7.71 & 78.81 & 8.19 & 76.99 & 7.67 & 76.73 & 8.42 & 0.042 & 78.49 & 7.93 \\
\hline Night systolic ambulatory BP at baseline & 100.37 & 12.27 & 102.63 & 12.72 & 110.94 & 13.63 & 110.00 & 14.11 & $<0.001$ & 103.26 & 13.39 \\
\hline Night diastolic ambulatory BP at baseline & 65.51 & 7.82 & 66.72 & 8.14 & 70.89 & 7.33 & 70.47 & 8.72 & $<0.001$ & 67.00 & 8.21 \\
\hline 24-h systolic ambulatory BP 2 years later & 117.79 & 13.33 & 117.73 & 13.22 & 117.29 & 12.82 & 116.08 & 14.20 & 0.79 & 117.50 & 13.34 \\
\hline 24-h diastolic ambulatory BP 2 years later & 74.31 & 6.97 & 72.81 & 6.70 & 74.66 & 8.22 & 73.46 & 7.86 & 0.19 & 73.95 & 7.20 \\
\hline Night diastolic ambulatory BP 2 years later & Percentage & $\mathrm{n}$ & Percentage & $\mathrm{n}$ & Percentage & $\mathrm{n}$ & Percentage & $\mathrm{n}$ & (Pearson's $\chi^{2}$ ) & Percentage & $\mathrm{n}$ \\
\hline Men & 43.28 & 145 & 36.97 & 44 & 50.70 & 36 & 32.00 & 24 & 0.08 & 41.50 & 249 \\
\hline Smoker & 5.37 & 18 & 5.04 & 6 & 15.49 & 11 & 6.67 & 5 & 0.02 & 6.67 & 40 \\
\hline ASF index & 37.01 & 124 & 35.29 & 42 & 38.03 & 27 & 40.00 & 30 & 0.93 & 37.17 & 223 \\
\hline Hypertensives at baseline & 23.88 & 80 & 17.65 & 21 & 16.90 & 12 & 22.67 & 17 & 0.38 & 21.67 & 130 \\
\hline Hypertensives 2 years later & 19.10 & 64 & 21.85 & 26 & 23.94 & 17 & 17.33 & 13 & 0.69 & 20.00 & 120 \\
\hline Hypertensive treatment 2 years later & 27.16 & 91 & 29.41 & 35 & 23.94 & 17 & 30.67 & 23 & 0.79 & 27.67 & 166 \\
\hline
\end{tabular}

Abbreviations: ASF, autonomic sleep fragmentation; BMI, body mass index; BP, blood pressure; D1, ND1, dipper, non-dipper at baseline; D2, ND2, dipper, non-dipper after 2 years.

Table 2 Autonomic nervous system activity characteristics at baseline of the study population according to the dipper/non-dipper status, using two measurements (means adjusted for hypertensive status at baseline)

\begin{tabular}{|c|c|c|c|c|c|c|c|c|c|c|c|}
\hline & \multicolumn{2}{|c|}{$D 1 / D 2$} & \multicolumn{2}{|c|}{$D 1 / N D 2$} & \multicolumn{2}{|c|}{ ND1/D2 } & \multicolumn{2}{|c|}{ ND1/ND2 } & \multirow{2}{*}{$\begin{array}{c}\text { (Fisher's test) } \\
\text { P }\end{array}$} & \multicolumn{2}{|c|}{ Total } \\
\hline & Mean & s.d. & Mean & s.d. & Mean & s.d. & Mean & s.d. & & Mean & s.d. \\
\hline In 24-h HF & 4.62 & 0.81 & 4.39 & 0.79 & 4.66 & 0.95 & 4.72 & 0.92 & 0.03 & 4.60 & 0.84 \\
\hline In 24-h LF & 5.40 & 0.63 & 5.18 & 0.71 & 5.40 & 0.67 & 5.27 & 0.78 & 0.02 & 5.31 & 0.67 \\
\hline In 24-h VLF & 6.39 & 0.57 & 6.18 & 0.65 & 6.43 & 0.55 & 6.32 & 0.66 & 0.005 & 6.33 & 0.60 \\
\hline In 24-h ULF & 7.77 & 0.60 & 7.69 & 0.69 & 7.76 & 0.60 & 7.79 & 0.61 & 0.65 & 7.77 & 0.62 \\
\hline In 24-h Ptot & 8.17 & 0.53 & 8.05 & 0.63 & 8.17 & 0.52 & 8.16 & 0.59 & 0.24 & 8.14 & 0.56 \\
\hline In night LF/HF & 0.98 & 0.63 & 0.98 & 0.71 & 0.98 & 0.71 & 0.84 & 0.63 & 0.36 & 0.95 & 0.66 \\
\hline In 24-h HR & 6.73 & 0.11 & 6.71 & 0.11 & 6.75 & 0.11 & 6.74 & 0.12 & 0.07 & 6.73 & 0.11 \\
\hline
\end{tabular}

Abbreviations: D1, ND1, dipper, non-dipper at baseline; D2, ND2, dipper, non-dipper after 2 years; HF, high frequency; LF, low frequency; Ptot, total frequency power; ULF, ultra-low frequency; VLF, very low frequency.

Among the dipper subjects at inclusion, the quartiles of the circadian variation of $\mathrm{BP}$ at 2 years were determined with the thresholds of 9.6, 14.9 and 19.4. The subjects in the fourth quartile (lower than 9.6) tended to have lower baseline ANS indices than those in the second (between 9.6 and 14.9) and third (between 14.9 and 19.4) quartiles. Differences were significant for LF and VLF (Figures 1 and 2). Adjustment for covariates did not modify this relationship. The mean baseline ANS activity indices were similar for the first (higher than 19.4) and fourth quartiles.

Among the non-dipper subjects at inclusion, the risk of shift to dipper status was not significantly associated with the ANS activity indices: $\mathrm{LF}(\mathrm{OR}=1.29[0.82-2.03], P=0.28), \mathrm{VLF}(\mathrm{OR}=1.36[0.27-$
1.36], $P=0.27)$ or $\mathrm{HF}(\mathrm{OR}=0.94[0.66-1.34], P=0.73)$ at baseline. The introduction of an antihypertensive treatment between the two examinations did not contribute to this shift $(P=0.63)$.

\section{DISCUSSION}

In this study, we investigated the association between ANS activity, its change over 2 years and the risk of shift to non-dipper status 2 years later in an untreated elderly study population. About $32 \%$ of the subjects changed status-from dipper to non-dipper or vice versa-2 years later, which is similar to Omboni et al.'s ${ }^{18}$ ' result (40\%) at 1 year of follow-up among exclusively hypertensive subjects who were younger than our subjects. 
Table 3 Univariate and multivariate analyses of the association between the autonomic nervous system activity indices and the non-dipper status after 2 years of follow-up, among the dippers at inclusion $(n=454)$

\begin{tabular}{|c|c|c|c|c|}
\hline & $O R$ & \multicolumn{2}{|c|}{$\mathrm{Cl}=95 \%$} & $P$ \\
\hline \multicolumn{5}{|l|}{ Univariate models } \\
\hline \multicolumn{5}{|l|}{ Indices at baseline } \\
\hline In 24-h HF & $0.74^{\mathrm{a}}$ & 0.54 & 0.96 & 0.02 \\
\hline In 24-h LF & $0.63^{\mathrm{a}}$ & 0.46 & 0.87 & 0.005 \\
\hline In 24-h VLF & $0.58^{\mathrm{a}}$ & 0.41 & 0.83 & 0.003 \\
\hline Day ambulatory systolic BP & $1.00^{\mathrm{a}}$ & 0.98 & 1.01 & 0.83 \\
\hline Day ambulatory diastolic BP & $1.00^{\mathrm{a}}$ & 0.97 & 1.02 & 0.75 \\
\hline Night ambulatory systolic BP & $1.02^{\mathrm{a}}$ & 1.00 & 1.03 & 0.08 \\
\hline Night ambulatory diastolic BP & $1.02^{\mathrm{a}}$ & 0.99 & 1.05 & 0.15 \\
\hline \multicolumn{5}{|l|}{ Change between two examinations } \\
\hline 24-h HF ( -10 to $10 \%)$ & 1 & & & 0.54 \\
\hline$>10 \%$ & 1.27 & 0.81 & 2.00 & 0.29 \\
\hline$\leqslant-10 \%$ & 1.33 & 0.59 & 2.99 & 0.49 \\
\hline 24-h LF ( -10 to $10 \%)$ & 1 & & & 0.08 \\
\hline$>10 \%$ & 1.90 & 1.03 & 3.49 & 0.04 \\
\hline$\leqslant-10 \%$ & 1.43 & 0.80 & 2.53 & 0.23 \\
\hline 24-h VLF ( -10 to $10 \%)$ & 1 & & & 0.04 \\
\hline$>10 \%$ & 2.57 & 1.16 & 5.70 & 0.02 \\
\hline$\leqslant-10 \%$ & 1.55 & 0.79 & 3.07 & 0.21 \\
\hline Day systolic BP (-10 to $10 \%)$ & 1 & & & 0.07 \\
\hline$>10 \%$ & 0.87 & 0.48 & 1.58 & 0.65 \\
\hline$\leqslant-10 \%$ & 1.79 & 1.05 & 3.06 & 0.03 \\
\hline Day diastolic BP ( -10 to $10 \%$ ) & 1 & & & 0.001 \\
\hline$>10 \%$ & 0.57 & 0.19 & 1.68 & 0.30 \\
\hline$\leqslant-10 \%$ & 2.71 & 1.57 & 4.65 & $<0.001$ \\
\hline Night systolic BP (-10 to $10 \%)$ & 1 & & & $<0.001$ \\
\hline$>10 \%$ & 2.86 & 1.82 & 4.48 & $<0.001$ \\
\hline$\leqslant-10 \%$ & 0.46 & 0.17 & 1.21 & 0.12 \\
\hline Night diastolic BP (-10 to $10 \%$ ) & 1 & & & 0.003 \\
\hline$>10 \%$ & 2.38 & 1.40 & 4.03 & 0.001 \\
\hline$\leqslant-10 \%$ & 0.89 & 0.48 & 1.64 & 0.70 \\
\hline \multicolumn{5}{|c|}{ Multivariate model (step-wise logistic regression) } \\
\hline In 24-h VLF & $0.61^{a}$ & 0.41 & 0.91 & 0.02 \\
\hline \multicolumn{5}{|l|}{ Change between two examinations } \\
\hline Day systolic BP (-10 to $10 \%)$ & 1 & & & $<0.001$ \\
\hline$>10 \%$ & 0.32 & 0.15 & 0.69 & 0.004 \\
\hline$\leqslant-10 \%$ & 3.70 & 1.79 & 7.65 & $<0.001$ \\
\hline Day diastolic BP (-10 to $10 \%)$ & 1 & & & $<0.001$ \\
\hline$>10 \%$ & 0.61 & 0.18 & 2.05 & 0.61 \\
\hline$\leqslant-10 \%$ & 3.88 & 1.96 & 7.69 & $<0.001$ \\
\hline Night systolic BP (-10 to $10 \%$ ) & 1 & & & $<0.001$ \\
\hline$>10 \%$ & 7.62 & 4.19 & 13.85 & $<0.001$ \\
\hline$\leqslant-10 \%$ & 0.15 & 0.05 & 0.45 & 0.001 \\
\hline
\end{tabular}

Abbreviations: $\mathrm{BP}$, blood pressure; $\mathrm{Cl}$, confidence interval; $\mathrm{HF}$, high frequency; LF, low frequency; OR, odds ratios; VLF, very low frequency.

aFor 1 s.d. increase.

In our study, we found that lower ANS activity, particularly lower sympathetic tone at baseline, was associated with an increased risk of shift to non-dipper status 2 years later.

The association between a lower VLF at baseline, a sympathetic component of HRV and a higher risk of shift to non-dipper status can be interpreted as an insidious global alteration of the HRV components at baseline because both lower sympathetic and parasympathetic components are related to the onset of impaired variation in circadian

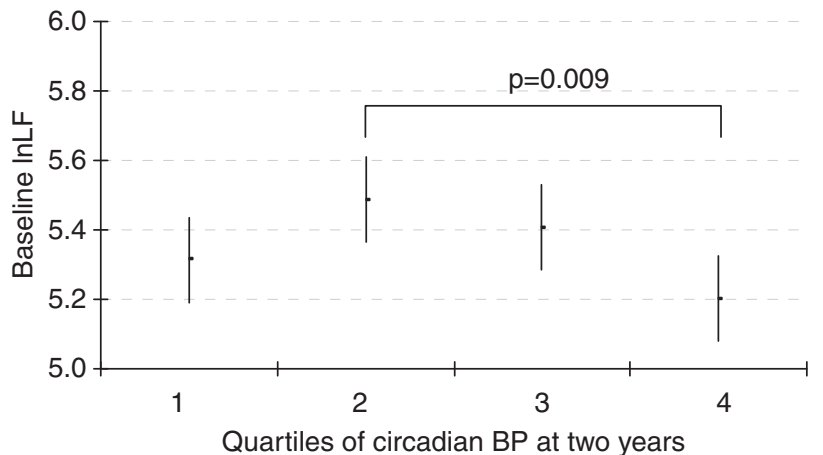

Figure 1 Baseline low frequency according to quartiles of circadian blood pressure 2 years later.

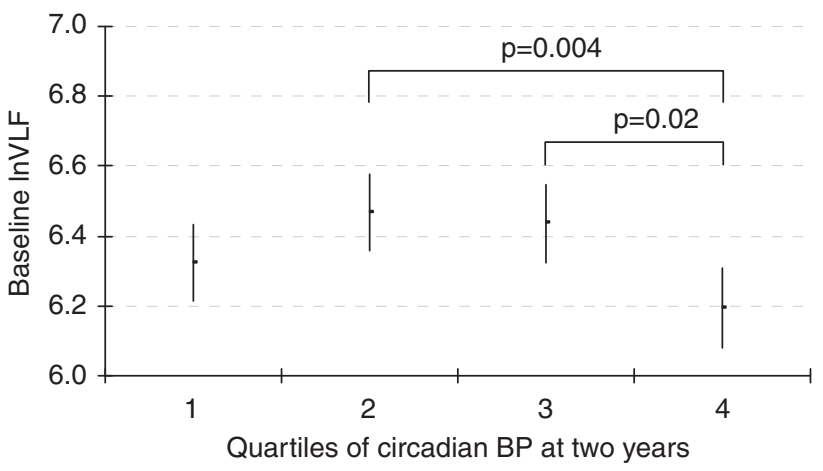

Figure 2 Baseline very low frequency according to quartiles of circadian blood pressure 2 years later.

BP observed at 2 years of follow-up. The multicollinearity between the HRV indices may explain why the VLF is the persistent significant variable in the multivariate analysis. In addition, the HRV response to parasympathetic tone decreases with age. ${ }^{20}$

Baseline HF tends to be higher, and the LF, VLF and LF/HF ratio tend to be lower, among non-dippers who remain non-dippers in comparison with dippers who remain dippers; nevertheless, the tests do not reach statistical significance. This observation suggests that the non-dipper phenomenon is more deleterious in terms of withinsubject autonomic nervous activity changes (variation across time) than between-subject changes (variation at a given time) in this study population. This inference is strengthened by our complementary multivariate analysis performed on the dipper subjects at baseline, which showed the prognostic values of baseline ANS activity indices and their within-subject changes over 2 years with respect to the shift to non-dipper status.

Previous cross-sectional studies have analyzed the relationship between dipper and non-dipper status defined with only one ABPM and ANS activity evaluated through $\mathrm{HRV}_{;}^{6,7}$ they showed that sympathetic components were lower among non-dipper subjects in different hypertensive populations. Our observations with longitudinal data confirm these results in an untreated population.

In a previous study, VLF was shown to be the component of HRV most associated with sleep-disordered breathing, particularly obstructive sleep apnea syndrome. ${ }^{21}$ We do not have data to confirm this hypothesis, but a previous study has shown that sleep-disordered breathing may be involved in the shift to the non-dipper pattern. ${ }^{22}$ 
Multivariate analysis showed that baseline VLF was associated with the risk of shift to non-dipper status independently of the BP level at baseline and its change between the two examinations. The risk of shift to non-dipper status was related to both day BP decrease and night BP increase between the two examinations. One possible interpretation of this association is that an increase in arterial stiffness, which reduces the sensitivity of baroreceptors, leads to poorer arterial $\mathrm{BP}$ adaptation under orthostatic conditions during the entire day (higher BP when lying down and lower BP when standing) and can lead to a shift to non-dipper status. The implication of VLF at baseline and BP change over 2 years in the risk of shift to non-dipper status may be supported by previous studies that have shown a significant relationship between obstructive sleep apneas and an increase in arterial stiffness. ${ }^{23,24}$

Several aspects of our results should be noted. The potential confounding effect of age in the studied relationship was controlled by the design of the PROOF study, in which the subjects had the same age at baseline. ${ }^{25}$ Dipper/non-dipper status was defined by systolic BP, which is recognized as a better predictor of morbidity and mortality than diastolic BP. ${ }^{3,6,7}$ A study by Boggia et al. ${ }^{26}$ supports a recommendation that the classification of dipper and non-dipper subjects be conducted with analyses using the continuous variation of arterial BP. In our study, we observed that the relationship between ANS indices and the circadian variation in BP seems to be non-linear. Subjects with insufficient circadian variation in BP had ANS indices that were similar to those of subjects with higher circadian variation. This result is supported by a previous study showing that extreme dipper and non-dipper patterns were associated with silent cerebrovascular damage. ${ }^{27}$

As the introduction of an antihypertensive treatment between the two examinations may have influenced the circadian variation in BP, we verified that withdrawing subjects who started taking such medications did not affect our results. Therefore, we chose to keep them in our analyses to maintain sufficient statistical power.

Our study has several limitations. The findings presented did not include the possible confounding effect of physical activity, which has been shown to have a significant impact on ANS activity indices. ${ }^{28}$ The results were adjusted for neither alcohol consumption nor quality of nighttime sleep; ${ }^{19}$ however, no difference in the autonomic sleep fragmentation index was observed between dipper and non-dipper status.

The reproducibility of dipper/non-dipper status has been questioned by some authors; it can, therefore, be argued that our study was exposed to classification bias. ${ }^{18}$ In addition, the repeated measurements of BP may expose the results to a regression toward the mean. However, we took these limitations into account in the analysis by adjusting the results for the baseline level of BP. We also completed the analysis by studying the quartiles of the circadian variation of BP after 2 years, which reinforced our results.

This study revealed a longitudinal association between impaired ANS activity and a shift to non-dipper status. Impaired ANS activity may alter BP regulation independently of BP level. This suggests that a strategy for treating cardiovascular disease should target, in addition to BP control, the recovery of a normal decrease in nocturnal BP. Further studies should be performed to analyze the potential role of arterial stiffness and sleep-related disorders in the relationship between ANS activity and an insufficient decrease in nocturnal BP.

\section{CONFLICT OF INTEREST}

The authors declare no conflict of interest.

\section{ACKNOWLEDGEMENTS}

The PROOF study was funded through three consecutive grants from the French Ministry of Health (Programmes Hospitaliers de Recherche Clinique: PHRC National PROOF, 1998; PHRC National SYNAPSE, 2002 and PHRC Regional Telamons, 2003).

1 Ben-Dov IZ, Kark JD, Ben-Ishay D, Mekler J, Ben-Arie L, Bursztyn M. Predictors of all-cause mortality in clinical ambulatory monitoring: unique aspects of blood pressure during sleep. Hypertension 2007; 49: 1235-1241.

2 Hoshide S, Kario K, Hoshide Y, Umeda Y, Hashimoto T, Kunii O, Ojima T, Shimada K. Associations between nondipping of nocturnal blood pressure decrease and cardiovascular target organ damage in strictly selected community-dwelling normotensives. Am J Hypertens 2003; 16: 434-438.

3 Kario K, Shimada K, Pickering TG. Abnormal nocturnal blood pressure falls in elderly hypertension: clinical significance and determinants. J Cardiovasc Pharmacol 2003; 41(Suppl 1): S61-S66.

4 Schroeder EB, Liao D, Chambless LE, Prineas RJ, Evans GW, Heiss G. Hypertension, blood pressure, and heart rate variability: the Atherosclerosis Risk in Communities (ARIC) study. Hypertension 2003; 42: 1106-1111.

5 Singh JP, Larson MG, Tsuji H, Evans JC, O'Donnell CJ, Levy D. Reduced heart rate variability and new-onset hypertension: insights into pathogenesis of hypertension: the Framingham Heart Study. Hypertension 1998; 32: 293-297.

6 Kario K, Motai K, Mitsuhashi T, Suzuki T, Nakagawa Y, Ikeda U, Matsuo T, Nakayama T, Shimada K. Autonomic nervous system dysfunction in elderly hypertensive patients with abnormal diurnal blood pressure variation: relation to silent cerebrovascular disease. Hypertension 1997; 30: 1504-1510.

7 Kohara K, Igase M, Maguchi M, Fukuoka T, Kitami Y, Hiwada K. Autonomic nervous function in essential hypertension in the elderly. Evaluation by power spectral analysis of heart rate variability. Am J Hypertens 1996; 9: 1084-1089.

8 Dodt C, Breckling U, Derad I, Fehm HL, Born J. Plasma epinephrine and norepinephrine concentrations of healthy humans associated with nighttime sleep and morning arousal. Hypertension 1997; 30(1 Part 1): 71-76.

9 Kario K, Schwartz JE, Pickering TG. Changes of nocturnal blood pressure dipping status in hypertensives by nighttime dosing of alpha-adrenergic blocker, doxazosin: results from the HALT study. Hypertension 2000; 35: 787-794.

10 Barthelemy JC, Pichot V, Dauphinot V, Celle S, Laurent B, Garcin A, Maudoux D, Kerleroux J, Lacour JR, Kossovsky M, Gaspoz JM, Roche F. Autonomic nervous system activity and decline as prognostic indicators of cardiovascular and cerebrovascular events: the 'PROOF' Study. Study design and population sample. Associations with sleep-related breathing disorders: the 'SYNAPSE' Study. Neuroepidemiology 2007; 29: 18-28.

11 Heart rate variability. Standards of measurement, physiological interpretation, and clinical use. Task Force of the European Society of Cardiology and the North American Society of Pacing and Electrophysiology. Eur Heart J 1996; 17: 354-381.

12 Lahiri MK, Kannankeril PJ, Goldberg JJ. Assessment of autonomic function in cardiovascular disease. J Am Coll Cardiol 2008; 51: 1725-1733.

13 Mancia G, De Backer G, Dominiczak A, Cifkova R, Fagard R, Germano G, Grassi G, Heagerty AM, Kjeldsen SE, Laurent S, Narkiewicz K, Ruilope L, Rynkiewicz A, Schmieder RE, Boudier HA, Zanchetti A, Vahanian A, Camm J, De Caterina R, Dean V, Dickstein K, Filippatos G, Funck-Brentano C, Hellemans I, Kristensen SD, McGregor K, Sechtem U, Silber S, Tendera M, Widimsky P, Zamorano JL, Erdine S, Kiowski W, Agabiti-Rosei E, Ambrosioni E, Lindholm LH, Viigimaa M, Adamopoulos S, AgabitiRosei E, Ambrosioni E, Bertomeu V, Clement D, Erdine S, Farsang C, Gaita D, Lip G, Mallion JM, Manolis AJ, Nilsson PM, O'Brien E, Ponikowski P, Redon J, Ruschitzka F, Tamargo J, van Zwieten P, Waeber B, Williams B, Management of Arterial Hypertension of the European Society of Hypertension; European Society of Cardiology. 2007 Guidelines for the Management of Arterial Hypertension. The Task Force for the Management of Arterial Hypertension of the European Society of Hypertension (ESH) and the European Society of Cardiology (ESC). J Hypertens 2007; 25: 1105-1187.

14 Staessen JA, Bieniaszewski L, O'Brien E, Gosse P, Hayashi H, Imai Y, Kawasaki T, Otsuka K, Palatini P, Thijs L, Fagard R. Nocturnal blood pressure fall on ambulatory monitoring in a large international database. The 'Ad Hoc' Working Group. Hypertension 1997; 29(1 Part 1): 30-39.

15 Roche F, Celle S, Pichot V, Barthelemy JC, Sforza E. Analysis of the interbeat interval increment to detect obstructive sleep apnoea/hypopnoea. Eur Respir J 2007; 29: 1206-1211.

16 Perciaccante A, Fiorentini A, Paris A, Serra P, Tubani L. Circadian rhythm of the autonomic nervous system in insulin resistant subjects with normoglycemia, impaired fasting glycemia, impaired glucose tolerance, type 2 diabetes mellitus. BMC Cardiovasc Disord 2006; 6: 19.

17 Grassi G, Dell'Orto S, Facchini A, Quarti Treveno F, Bolla GB, Mancia G. Effect of central and peripheral body fat distribution on sympathetic and baroreflex function in obese normotensives. J Hypertens 2004; 22: 2363-2369.

18 Omboni S, Parati G, Palatini P, Vanasia A, Muiesan ML, Cuspidi C, Mancia G. Reproducibility and clinical value of nocturnal hypotension: prospective evidence from the SAMPLE study. Study on Ambulatory Monitoring of Pressure and Lisinopril Evaluation. J Hypertens 1998; 16: 733-738. 
19 Manning G, Rushton L, Donnelly R, Millar-Craig MW. Variability of diurnal changes in ambulatory blood pressure and nocturnal dipping status in untreated hypertensive and normotensive subjects. Am J Hypertens 2000; 13: 1035-1038.

20 Goldberger JJ, Challapalli S, Tung R, Parker MA, Kadish AH. Relationship of heart rate variability to parasympathetic effect. Circulation 2001; 103: 1977-1983.

21 Szollosi I, Krum H, Kaye D, Naughton MT. Sleep apnea in heart failure increases heart rate variability and sympathetic dominance. Sleep 2007; 30: 1509-1514.

22 Mae Hla K, Young T, Finn L, Peppard PE, Szklo-Coxe M, Stubbs M. Longitudinal association of sleep-disordered breathing and nondipping of nocturnal blood pressure in the Wisconsin sleep cohort study. Sleep 2008; 31: 795-800.

23 Jelic S, Bartels MN, Mateika JH, Ngai P, DeMeersman RE, Basner RC. Arterial stiffness increases during obstructive sleep apneas. Sleep 2002; 25: 850-855.

24 Drager LF, Bortolotto LA, Figueiredo AC, Silva BC, Krieger EM, Lorenzi-Filho G. Obstructive sleep apnea, hypertension, and their interaction on arterial stiffness and heart remodelling. Chest 2007; 131: 1379-1386.
25 Umetani K, Singer DH, McCraty R, Atkinson M. Twenty-four hour time domain heart rate variability and heart rate: relations to age and gender over nine decades. J Am Coll Cardiol 1998; 31: 593-601.

26 Boggia J, Li Y, Thijs L, Hansen TW, Kikuya M, Bjorklund-Bodegard K, Richart T, Ohkubo T, Kuznetsova T, Torp-Pedersen C, Lind L, Ibsen H, Imai $Y$, Wang J, Sandoya E, O'Brien E, Staessen JA. Prognostic accuracy of day versus night ambulatory blood pressure: a cohort study. Lancet 2007; 370: 1219-1229.

27 Kario K, Matsuo T, Kobayashi H, Imiya M, Matsuo M, Shimada K. Nocturnal fall of blood pressure and silent cerebrovascular damage in elderly hypertensive patients. Advanced silent cerebrovascular damage in extreme dippers. Hypertension 1996; 27: 130-135.

28 Pickering TG, Harshfield GA, Kleinert HD, Blank S, Laragh JH. Blood pressure during normal daily activities, sleep, and exercise. Comparison of values in normal and hypertensive subjects. JAMA 1982; 247: 992-996. 